\title{
ENOCH CARNEIRO: UM INTELECTUAL DE COMUNIDADE
}

\author{
Eduardo Pereira Lopes ${ }^{1}$
}

Resumo: Este trabalho propõe alavancar a discussão sobre a figura do intelectual contemporâneo, especialmente na literatura. Para isso, apresentamos Enoch Carneiro, um escritor marginal, como exemplo de intelectual contemporâneo. Mostramos que o engajamento surge em sua obra a partir da estreita relação entre compromisso social, atrelado ao contexto de sua cidade natal, com a ideia de que o papel responsável que o autor chama para si, enquanto escritor, é construído na associação de sua literatura, engajamento autoral e outros discursos sociais como o movimento estudantil, confeccionando assim o que chamamos de intelectual de comunidade.

Palavras-Chave: Enoch Carneiro, Literatura, Engajemento.

Abstract: This work intends stimulate a discussion about the modern intellectual, especially in the literature. For this, we show Enoch Carneiro, a marginal writer, as an example of nowadays intellectual. We showed that engagement starts in his work beginning of this straight relationship between social compromise, concerning to the his homeland, with the idea that the responsible act that the author call to yourself, as a writer, is constructed in association of his literature, authorial engagement and other social discourses with the student organization, constructing this way what we named of community intellectual.

Keywords: Enoch Carneiro, Literature, Engagement.

\section{INTRODUÇÃO}

Enoch Carneiro nasceu em Uibaí (BA), em 24 de março de 1957. Começou na literatura pela poesia nos anos 80, época em que participou do movimento Poetas da Praça, em Salvador. Nesse tempo, lançou Delírio solitário, Maria meu bem e Impossível silêncio, obras que

1 Docente do Instituto Federal de Educação da Bahia (IFBA); Mestre em Literatura e Diversidade Cultural pela Universidade Estadual de Feira de Santana (UEFS). Endereço eletrônico: duduquixalopes@hotmail.com. 
circularam na região do autor, firmando sua imagem na comunidade como um escritor engajado.

Das noções de engajamento, a que mais corresponde ao projeto literário de Enoch Carneiro é a que encontramos em Simone Beauvoir, na obra A força das coisas (1963). Para ela, engajamento é a presença total do escritor na escrita. Quer dizer, o escritor confunde-se com o texto. Escritor e literatura representam-se simultaneamente; mais que isso, tal fato diz respeito ao compromisso e à responsabilidade que são gerados ao se produzir uma obra literária. Se escritor e escrita se confundem, escrever não é outra coisa senão se colocar na posição de ser jugado e/ou de receber críticas através da obra. Aprovação e reprovação serão sempre espectros dos críticos e dos julgamentos que o escritor poderá enfrentar.

Ao analisarmos a trajetória de vida de Enoch Carneiro, pode-se dizer que ele é adepto dessa teoria. Primeiramente porque não se preocupa em se intimidar com julgamentos ou eximir-se da responsabilidade que seu engajamento acarreta. Por exemplo, por ser escritor marginal, dono de uma leitura não tão fácil, o que pode não agradar a um leitor desavisado, sabe lidar bem com as rejeições e as críticas. Afinal, o escritor engajado não procura safar-se de sua responsabilidade pelo subterfúgio da liberdade na criação literária. Para este escritor, não há licença poética alguma, o que há é o “[...] dever de provocar o escândalo e por direito imprescritível escapar das suas consequências” (SARTRE apud DENIS, 2002, p. 47).

À escrita engajada não é permitido recair punições decorrentes de nenhum "escândalo”, pois o processo de criação é ato livre. Embora em muitos momentos da história escrever engajadamente tenha sido escrever perigosamente, como diria Albert Camus ${ }^{2}$. Assim, a presença máxima do homem Enoch Carneiro em sua obra é o espelho da sua biografia, pois podemos afirmar que ele escreveu, praticamente, aquilo que viveu. Ao parafrasear o discurso de Sartre, ele aplica ao seu texto aquilo que o escritor francês discorre sobre a relação entre ficção e realidade, mais especificamente quando diz que a ficção deve ser um instrumento de acesso ao real (SARTRE apud SOUZA, 2008, p. 60).

A matiz sartreana da prosa comprometida de Carneiro está no fato de o signo não ser coisa, mas sim instrumento, pois a palavra é ação e o escritor, ao dar nome e “denunciar” a

2 O próprio Enoch Carneiro, quando Poeta da Praça, fora detido algumas vezes pela polícia, em decorrência de “atos obscenos” em praça pública. 
Pontos de Interrogação, v. 3, n. 1, jan./jul. 2013

Revista do Programa de Pós-Graduação em Crítica Cultural

Universidade do Estado da Bahia (UNEB), Campus II - Alagoinhas - BA

realidade, abre passagem para a sua transformação. Nesse sentido, escreve para se sentir útil. Mas se sentir especificamente útil a quem? Para onde ele direciona seu engajamento? Numa primeira instância, todo escritor é útil ao mundo e ao seu tempo, ele estabelece esse diálogo “prático” com o universo enquanto um interlocutor, o que, para nós, no caso de Enoch, é a sua cidade natal. É no diálogo com a cidade que o autor contata o mundo. Nesse sentido, “o mundo está em Uibaí”.

No livro de história memorialista, Canabrava do Gonçalo, escrito por Osvaldo Alencar Rocha e Edimário Oliveira Machado, percebemos uma narrativa que tenta o reconhecimento de uma identidade uibaiense. Para tanto, os autores, na segunda parte da obra, após apresentarem a história de fundação e a genealogia do lugar, trazem ao leitor um rápido panorama dos literatos da terra. A lógica é que a cultura local, especialmente a literatura, detém o poder simbólico de definir o seu povo ao diferenciá-lo do outro. Desse modo, a identidade da cidade também passa pela criação literária. Os autores revelam a veia artística da cidade, quando afirmam que:

\begin{abstract}
A família uibaiense é rica em anedotistas, contadores de "causos”, repentistas, ceresteiros (sic), charadistas e poetas populares. No passado tivemos o velho Bié, Arnobinho, Liobino, Firmício; sem falar em Faustino e tantos outros, que pelas dificuldades em publicarem arte, tiveram seus versos, estórias e anedotas esquecidas pela ação do tempo. [...].

Mas as artes em Uibaí não são coisa do passado. A cultura do povo, viva e opulenta, estampa um cartel de artistas da atualidade, no qual podemos enumerar, sem prejuízo de tantos outros, Maninho Leví e o som deslumbrante de seu Bandolim; Valmir Rosa e Messias de Floripe, puxando o coro dos mestres do violão; Nemí, Armitão, Beto, Carlinhos e Galego, com suas vozes sempre presentes; Tonico e Zé Índio, compositores, poetas da música; Antonhão e suas esculturas, em voluntário anonimato; Enoch Carneiro e Renato Carvalho, com a poesia inquieta; Nezim e o repente popular; Gió, com suas charadas e anedotas; Honório e seu verso distante; Major Tobias, com suas canções, estórias e raizadas; e tantos filhos da terra que fermentam a vida cultural da cidade com sua veia artística. (ROCHA; MACHADO, 1988, p. 189).
\end{abstract}

A cidade é conhecida na cena cultural da região como uma terra amiga das artes e, sobretudo, por engajá-las às questões políticas. Enoch Carneiro é o primeiro artista que se destaca pela palavra escrita. Antes dele já se conhecia alguns literatos da palavra oral, poetas e contadores de causos, como vimos na citação de Rocha e Machado (1988). Atualmente, e fazendo um apanhado rápido da produção literária uibaiense, registramos a presença do poeta e contista Pita Paiva com quatro livros lançados: Uma escada pro futuro (1994), Um deus que dança (1999), Um conto de cada canto (2009), e Tudo dá poesia (2011). Temos, ainda, Ari Oliveira 
Machado, com o livro Versos e poemas diversos (2012), além de Alan Oliveira Machado, com Bestiário de infância (2001), isso só para citar alguns.

\section{ENGAJAMENTO PELA COMUNIDADE}

Enoch Carneiro possui uma trajetória de vida engajada em prol de um tripé arte-culturapolítica, mas ele não seria uma figura isolada ou extraordinária. É, antes de tudo, fruto de uma região inserida em uma forte dinâmica de contracultura. Uibaí não era a única cidade na região onde se desenvolviam traços dessa contracultura enviesada politicamente. Xique-Xique, Central, Barra do Mendes, Presidente Dutra, Irecê, tinham entidades que promoviam e mantinham esse foco de contracultura, como casas e organizações de estudantes. Porém, havia naquela cidade uma especificidade que residia em torno da figura de Osvaldo Alencar advinda da candidatura em 1976, momento de enfrentamento do partido da ditadura. Depois, também a atuação de Tarcísio Machado na campanha de 1988 deixou um marca de organização popular de viés esquerdista.

Enoch é um intelectual fruto dessa dinâmica regional de lutas políticas, envolvido pela tríplice ação: estudar-retornar-engajar. Afinal, os jovens da cidade iam morar em casa de estudante na capital - onde se atualizavam politicamente numa linha de esquerda, depois retornavam para a região e, então, através das lições aprendidas, engajavam-se nos movimentos políticos locais. Diversas formas de engajamento eram postas em prática, as mais comuns eram eventos realizados pelas organizações estudantis. Enoch Carneiro foi um dos fundadores da CEU (Casa do Estudante de Uibaí) e um dos membros mais influentes, principalmente para aqueles que foram contemporâneos seus. Ações como organização das semanas de arte, do São João, lançamentos de livro, recitais, foram marcando a linha de engajamento de Carneiro e definindo a sua forma de contribuir com o desenvolvimento político e cultural de sua terra natal.

Historicamente, as casas de estudantes em Salvador serviram como mecanismo estratégico de reprodução das classes dominantes locais, perpetuando assim as desigualdades sociais (MARTINS, F., 2006). A CEU foi fundada pela Associação dos Estudantes Universitários e Secundaristas de Uibaí (AEUSU), em 1973. Da assembleia fundadora a maior parte dos residentes eram filhos das camadas dominantes locais: “Tratava-se, portanto, de filhos da camada 
Pontos de Interrogação, v. 3, n. 1, jan./jul. 2013

Revista do Programa de Pós-Graduação em Crítica Cultural

Universidade do Estado da Bahia (UNEB), Campus II - Alagoinhas - BA

dominante comercial e camponesa, que além da classe dominante econômica, era quem fornecia os quadros políticos do poder público municipal” (MARTINS, F., 2006, p. 11).

Com o passar do tempo, a cena estudantil dos uibaienses em Salvador foi mudando. Gradativamente, devido às divergências ideológicas, o auxílio que a Prefeitura Municipal destinava à CEU foi diminuindo na medida em que os filhos das elites locais iam deixando a residência. Martins (2006, p. 12) mostra como o financiamento à CEU, por parte da prefeitura uibaiense, que era integral em 1973, foi decaindo ao longo dos anos, sendo totalmente suspenso em 1981. Nesse clima, principalmente na década de 1980, acende-se na CEU um entusiasmo pela luta estudantil, voltada para a esquerda, pela reestruturação e implantação de uma política estudantil municipal ${ }^{3}$, luta essa associada e estimulada por uma conjuntura de outras lutas de caráter nacional, como as Diretas Já. Desde então, Enoch Carneiro e todos aqueles que queriam ver mais oportunidades para os menos favorecidos começariam uma luta de ações esporádicas, mesmo com todas as adversidades, contra os mecanismos autoritários e retrógrados das camadas dominantes na política local.

A postura intelectual que se observa no engajamento de Enoch Carneiro é do intelectual de comunidade. Trata-se de um engajamento relacionado sobremaneira com as questões da cidade, que passam pela crítica às más administrações políticas, até o elogio à cidade.

Qualquer consciência de marginal está presente em uma literatura como a de Enoch Carneiro. Sua prosa é nesse sentido guardadora de uma característica da literatura menor de que falam Deleuze e Guatari (2003), pois nela tudo é político. As questões individuais, ou locais, estão diretamente ligadas ao político: “A questão individual, ampliada ao microscópio, torna-se muito mais necessária, indispensável, pois outra história se agita no interior” (DELEUZE, GUATARI, 2003, p. 39). O individual em Enoch Carneiro é explorado com o objetivo de acessar aspectos referentes ao político e ao coletivo. Basta vermos o livro 50 anos depois, que se poderia chamar de uma ode à cidade, onde o autor, escrevendo na fronteira entre literatura e história, tematiza, entre outros assuntos, a memória local. Ele acessa temas

3 É constante nas publicações da CEU e da Confederação Interiorana de Vestibulandos e Universitários da Bahia (CIVUB), a reivindicação pelo restabelecimento de uma política de assistência estudantil para as residências do interior, a solicitação do apoio de todos para que as residências estudantis sejam mantidas, para que o aumento da precariedade seja detido, para que as condições mínimas de dignidade sejam oferecidas aos estudantes residentes (MARTINS, 2006). 
universais através do particular, mas tudo deságua na política, que nunca foi em sua obra pano de fundo para trama do particular, como nas literaturas “maiores”, de perfil não engajado.

Mesmo ainda visto como um intelectual responsável, atualmente se questiona o engajamento da obra de Enoch Carneiro. Seria um escritor bonvivant, por ter se tornado portador de um engajamento moderado, sem buscar uma transformação social radical, mas somente questionar alguns valores.

É uma visão dos fatos ingênua, esperar que as transformações e mutações pelas quais o capitalismo deve naturalmente passar continuem acontecendo diante do olhar da crítica que o acompanha, e achar que ela irá permanecer estática, vendo o seu alvo passando e transformando-se. Ora, a crítica do sistema ou a força contraditória que o acompanha inevitavelmente orbita em torno dela. Isso é inexorável. Existe uma crítica persistente da sociedade capitalista na obra de Enoch Carneiro que é tão heterogênea quanto as forças que constroem essa sociedade. Foucault e Deleuze ${ }^{4}$ já alertaram para o fato de que "as forças de poder/desejo/interesse são tão heterogêneas que sua redução a uma narrativa coerente, é contraproducente” (SPIVAK, 2010, p. 22). Então, por que cobrar coerência na narrativa de Enoch? Não seria também contraproducente?

A natureza heterogênea da narrativa/discurso na prosa de Enoch Carneiro não retira o seu caráter de engajado. Não há por que existir uma narrativa de engajamento homogêneo. O que existe é um discurso engajado heterogêneo e fragmentado, assim como o sistema a que ele faz oposição. O escritor exerce seu papel ao lado do poder, o compromisso do intelectual em relação a esse poder constitui uma missão que é "tentar revelar e conhecer o discurso do Outro na sociedade” (SPIVAK, 2010, p. 22). O “Outro” em Enoch Carneiro aparece no oprimido, apresentado pelas forças econômicas que o exploram no Sertão. Em sentido lato, o “Outro” é toda a humanidade que vive sob a ilusão de falsa felicidade na sociedade de consumo (tema que perpassa os livros de Enoch Carneiro).

O engajamento contemporâneo na literatura não tem bandeira com uma foice e um martelo. Mas também não hasteia em seu mastro a representação do niilismo. O engajamento em Enoch Carneiro não é oclusivo, pois o “Outro” não é apenas a classe trabalhadora, ele não

4 Diálogo entre Foucault e Deleuze em “Os intelectuais e o poder”. In: Microfisica do poder. 1979. 
Pontos de Interrogação, v. 3, n. 1, jan./jul. 2013

Revista do Programa de Pós-Graduação em Crítica Cultural

Universidade do Estado da Bahia (UNEB), Campus II - Alagoinhas - BA

procura semelhança direta com as formas tradicionais de engajamento de influência marxista. É uma questão de teoria e prática em que a interpretação crítica do sistema é a teoria, enquanto o engajamento é a prática. Porém, as relações teoria-prática são parciais e fragmentárias (FOUCAULT; DELEUZE, 1979). Toda teoria (o Marxismo, por exemplo) enfrenta resistência, e essa resistência deve ser superada pela prática. No âmbito da literatura, a prática é levada a cabo pela sua ação intelectual. Contudo, como adverte Foucault (1979), os intelectuais descobriram que a massa não precisa deles para saber, elas sabem perfeitamente.

A literatura engajada não é veículo da verdade de nenhuma massa. Essa ideia sobre a literatura seria parte do discurso de poder, ao pensar que os oprimidos são dependentes de um indivíduo para pensar a sua situação, mas um indivíduo fora de sua classe, pensando e orientando-os ideologicamente. Ser agente do pobre como se este fosse um deficiente visual e o intelectual o garotinho que o ajuda, indefeso, a atravessar a avenida cheia de perigos, não é esta a pretensão do engajamento de Enoch Carneiro, pois

\footnotetext{
O papel do intelectual não é mais o de se colocar "um pouco na frente ou um pouco de lado" para dizer a muda verdade de todos; é antes, o de lutar contra as formas de poder exatamente onde ele é, o objeto e o instrumento: na ordem do saber da "verdade", da "consciência", do discurso. E por isso que a teoria não expressará, não traduzirá, não aplicará uma prática, ela é uma prática. Mas regional e local [...] não totalizadora (FOUCAULT; DELEUZE, 1979, p. 42).
}

Enoch Carneiro é um intelectual das massas, mas não de massa. Em toda literatura marginal engajada podemos perceber a conclusão de que as massas verdadeiramente pensam e tem consciência, pois a incapacidade de fazer isso se fundamenta no raciocínio, segundo Foucault (1979), do projeto hegemônico de poder e dominação cultural que as elites estabeleceram de que elas precisam de um intelectual para guiá-las, como algo pensado apenas para alargar ainda mais o fosse entre elas e as classes desfavorecidas.

Enoch Carneiro, escritor e intelectual de comunidade, desenvolvia um engajamento de intelectual do tipo estruturalista, ou seja, aquele defensor de que teoria comprova-se com prática. Mas, quando ele vive a crise das verdades homogeneizantes, seu engajamento socialista entra em xeque pela ausência da prática. Todavia, percebemos que não há diferenciação entre teoria e prática, pois elas são partes de um mesmo empreendimento. Esse é o papel intelectual que percebemos em Enoch: não é mais o do esclarecedor, mas o de que quem, como qualquer subalterno “fala”, também fala. Sem discordarmos de Foucault, pensamos que o intelectual 
nem dá a voz, nem dá a consciência, tampouco mostra a verdade, mas reconhecemos que ele dá visibilidade à consciência das massas, sobretudo quando esta e a do autor são as mesmas ${ }^{5}$.

Vimos acima a compreensão do papel intelectual em Enoch Carneiro sob o ponto de vista foucaultiano. Do ponto de vista marxista, esta representação não é a de um escritor burguês, no sentido pejorativo de classe opressora e detentora dos meios de produção. Mas havemos de concordar que na "segunda fase” 6 , Enoch Carneiro é burguês no sentido revolucionário do termo, pois representa uma gama de ideais perseguidos pelos intelectuais iluministas, não que isso signifique ser reacionário. Ele se considera um iluminista, entusiasta de Rousseau e do seu Contrato social. Polemiza ao afirmar que não é preciso matar Marx, porque ele já está morrendo. Mas reconhece que, se o socialismo fracassou, “o cara” (Marx) está vivo ainda $\operatorname{assim}^{7}$. Não considera sua literatura engajada no sentido marxista, mas sim dona de uma expressão comprometida. Em todos os livros, há uma tendência muito clara de que não se deve confiar tudo ao Estado ${ }^{8}$.

Podemos observar em seu discurso que a concepção que tem de si, enquanto escritor, é a do intelectual muito mais iluminista porque pensa o Estado, critica o seu poder e lembra que tal poder emana do povo. É na regulação e fiscalização no campo do “contrato” entre povo e Estado que reside a noção de ética do autor, pois, de acordo com ele, "nenhuma das partes pode romper com suas respectivas obrigações”.

Enoch Carneiro chega à ética por meio do homem, analogamente a um dos maiores intelectuais do pensamento iluminista burguês, Rousseau, pois este, em seu Discurso sobre a origem e os fundamentos da desigualdade entre os homens, reflete acerca da natureza da desigualdade dos homens. Para o filósofo, uma é de origem natural, outra,

[...] que se pode chamar de desigualdade moral ou política, porque depende de uma espécie de convenção, e que é estabelecida ou, pelo menos, autorizada pelo consentimento dos homens. Con-

5 É interessante notar que o discurso e o saber do qual à literatura marginal é negada a voz, somente pode aparecer nos espaços regionais e locais onde mutuamente escritor e leitor, massa e intelectual, se encontram, por estarem no mesma situação, em relação ao discurso dominante. Além disso, nessa concepção, o modelo intelectual não é mais aquele modelo sartreano rígido em que o intelectual não pertence à classe daqueles que o seu discurso dá visibilidade.

6 Período que se compreende entre as publicações Além das ilusões (2001) e 50 anos depois (2011).

7 Depoimento de Enoch Carneiro, concedido a Eduardo Lopes, em Uibaí, em 05 de novembro de 2012.

8 Depoimento de Enoch Carneiro, anteriormente citado. 
Pontos de Interrogação, v. 3, n. 1, jan./jul. 2013

Revista do Programa de Pós-Graduação em Crítica Cultural

Universidade do Estado da Bahia (UNEB), Campus II - Alagoinhas - BA

siste esta nos diferentes privilégios de que gozam alguns com prejuízo dos outros, como ser mais ricos, mais honrados, mais poderosos do que os outros, ou mesmo fazerem-se obedecer por eles (ROUSSEAU, 2006, p. 31).

Enoch Carneiro pratica um discurso ético do intelectual socialista. De um lado, é uma voz contrária ao sistema, do outro, pratica o discurso ético do intelectual iluminista por estar engajado nas reformas do estado e na defesa do princípio da igualdade entre os homens e de valores como justiça, fraternidade e liberdade. A busca por tais valores vai desaguar - após a falência do projeto socialista e da prática engajada socialista na poesia - na obra Um nordestino em Moscou, com o exercício do espírito reformista do Iluminismo em seus romances.

Escritor híbrido, Enoch Carneiro descende do Iluminismo, mas também é “feito” de várias correntes de pensamento que o atravessam e o influenciam ${ }^{9}$. Dessa filosofia de reinvenção social, herdou a ideia de progresso e de aperfeiçoamento moral dos homens. O comprometimento por justiça social se funda ao ideal de justiça pregado pelos iluministas.

Talvez, devido à proximidade do Iluminismo com as duas forças que "disputam” o mundo - o liberalismo e o marxismo - é que se pode confundir um escritor de ideologia marxista, porém adaptada à pós-modernidade, com um posicionamento ideológico liberal.

\section{O PERFIL INTELECTUAL}

O Iluminismo, como precursor ideológico do intelectual moderno, é responsável pela construção do intelectual como um homem bom. Pois a ele não bastava apenas pronunciar a verdade, mas, também, ser bom. Nascia, assim, uma tradição de homens que “[...] não só se pronunciam verdadeiramente sobre as coisas do mundo como também são guardiões do bem contra o mal” (RIBEIRO, 2004, p. 70).

Uma das crises do intelectual hoje, bem como do esvaziamento de seu estatuto de oráculo do caminho certo, é que na sociedade pós-moderna o “mal” não está mais identificado como antes ${ }^{10}$. É praticamente impossível ao intelectual contemporâneo perseguir “o bem”,

9 Marxismo, Kardecismo, Iluminismo.

10 Esse “antes” encontra exemplo fácil na Guerra Fria. Para os intelectuais de esquerda, até a segunda metade do século XX, era fácil identificar o inimigo da revolução socialista. 
pois, com a “[...] desvalorização do político, o esfriamento do messianismo ou, pelo menos, a dificuldade para lhe encontrar as formas sociais e culturais possíveis, desguarnece-se também o intelectual, fragilizando-se e perdendo a aura de locutor da esperança” (RIBEIRO, 2004, p. 70).

Na realidade brasileira, podemos pensar na fundação do intelectual contemporâneo via constituição de 1988. Enoch Carneiro é influenciado por esta constituição. Atualmente sua prosa assume a presença de um intelectual burguês progressista nos moldes políticos do iluminismo burguês. Apresenta um engajamento corretivo do sistema, mas não a defesa da destruição ou substituição desse sistema. Em seus últimos livros, percebe-se a presença e o resultado do triunfo da constituição de 1988. É a busca da cidadania, da militância política e da formação de uma crítica social como resultado direto da consolidação das conquistas provenientes da constituição cidadã. É o triunfo do Estado Democrático de Direito e da adoção do caminho legal para a conquista dos direitos do cidadão. Percebe-se que o caminho tomado é o de um sistema pautado na ética, porém dentro dos marcos da democracia burguesa.

O intelectual fragmentado não busca mais a revolução no sentido moderno do termo. Não quer dizer que o intelectual esteja morto, como muitos defendem ao confundir em alteração de performance com desaparecimento do papel. “Os intelectuais não acabaram”, assegura Ribeiro (2004), “mudou sua natureza e tornou-se complexa sua formação”. Hoje ele age no comunitarismo, não indica mais o caminho das pedras. "Tornou-se claro que hoje o intelectual age organizado, intervindo, criando” (RIBEIRO, 2004, p. 74). O intelectual de hoje trabalha em equipe, em projetos, revelando a consciência de responsabilidade em relação ao seu tempo “ultrapassando o livro, o ato livresco” (RIBEIRO, 2004, p. 76). Nesse sentido, Enoch Carneiro é um intelectual que “age organizado”, como vimos na sua relação com o movimento estudantil, afinal, ele articula a literatura com outras linguagens sociais.

Com isso, Enoch Carneiro se firma como o escritor da cidade, intelectual de comunidade, com o perfil de um intelectual flexível em muitas linguagens e abordagens sociais. Enquadrá-lo ou eleger um perfil intelectual representativo de seu trabalho e história de vida não é tarefa fácil. Assim, propomos o conceito de literatura de comunidade por se definir como uma prática literária engajada. Associada a outras linguagens artísticas, e outros discursos, como o político, ela exerce o seu papel de uma arte híbrida e comprometida com as questões de seu tempo, se colocando como elemento de ação em prol da transformação política de uma comu- 
Pontos de Interrogação, v. 3, n. 1, jan./jul. 2013

Revista do Programa de Pós-Graduação em Crítica Cultural

Universidade do Estado da Bahia (UNEB), Campus II - Alagoinhas - BA

nidade. Para Lemos (2010), essa associação da literatura com outros discursos vem compensar a perda do papel da literatura como gênero privilegiado da pauta política. Nesse sentido, a autora argumenta que:

\begin{abstract}
A literatura, que tem perdido seu papel privilegiado como discurso dos possíveis, por outro lado, tem gerado novas formas de expressão, híbridas, em combinação com outros gêneros que têm trazido uma abertura importante como espaço das possibilidades, de acordo com as demandas culturais do mundo contemporâneo (LEMOS, 2010, p. 70).
\end{abstract}

Tomemos como exemplo a literatura de comunidade de Enoch Carneiro, primeiramente, pelo papel responsável em torno de um projeto específico de comunidade (uma sociedade administrada dentro de um viés político ético-progressista), depois, pela contribuição dada à comunidade através da palavra escrita e, por fim, pela associação dessa palavra com ações concretas, como a criação das entidades de cunho político e comunitário encabeçadas por Enoch Carneiro: Arte Som e FAU, a primeira, atuando na arte, enquanto a segunda, em comunicação social.

O amigo e colega de luta de Enoch Carneiro, Osvaldo Alencar, fez a apresentação do livro Um nordestino em Moscou (1990), retratando a imagem do autor como um escritor engajado, com o perfil de “[...] um caminheiro em busca da palavra nova, do verso cadente, capaz de traduzir as contradições de um país absurdo com o qual jamais se conformou” (ROCHA, 1991). Percebemos que o comprometimento regional, na prosa de Enoch Carneiro, parece haver um cosmopolitismo do pobre, parafraseando Silviano Santiago, pois ele escreve em nome do subalterno, quer seja das margens do São Francisco - em Xique-Xique -, quer seja de uma fazenda que emprega trabalho infantil no norte do país. O enredo, o espaço, as personagens podem ser locais, porém o discurso tangencia várias realidades, espaços, tempos e categorias sociais.

É dessa forma, como um sujeito que pensa a realidade, refletindo criticamente sobre o mundo, procurando sempre “a palavra nova”, o "verso cadente”, que Enoch Carneiro é visto pelos intelectuais conterrâneos e contemporâneos. A descrição feita por Osvaldo Alencar Rocha, algumas linhas atrás, nos mostra traços importantes do escritor Enoch Carneiro, principalmente pela vivência engajada e pelo uso da literatura como trombeta. Por isso, torna-se válido pesquisar o reconhecimento de Enoch Carneiro junto de alguns dos intelectuais com os quais ele manteve, ou mantém estreita relação. 
Podemos traçar um perfil do reconhecimento do escritor Enoch Carneiro, a partir da versão de intelectuais por ele influenciados, especialmente na década de 1980 e início de 1990. Dessa geração, posterior à sua, da qual, sem medo de errar, Enoch foi o grande nome na literatura. Entrevistando alguns desses intelectuais foi possível perceber o que a sua história de vida e a sua literatura representa para eles.

Pita Paiva, ou simplesmente Pita, como é conhecido em Uibaí, fez parte de uma geração composta pelos jovens que, durante a década de 90, saíram para estudar fora da cidade e tiveram de residir na CEU, e que viveram suas mazelas e suas glórias. Depois de se formar, política e profissionalmente, Pita Paiva construiu sua trajetória militando nos movimento de contracultura da cidade. Atualmente é um escritor bem conhecido no Território de Identidade de Irecê. Possui quatro obras publicadas, certamente é o escritor de Uibaí com mais livros vencedores de editais, de maior tiragem, venda e distribuição nas escolas.

Pita Paiva sempre viu a figura de Enoch Carneiro como um sujeito de uma inquietação social muito grande, além de sempre estar buscando alternativas de se fazer algo pela cidade. Pita Paiva explica que:

[...] a primeira vez que tive contato com Enoch foi na sala de aula, pois naquela época início da década de 80 a CEU tinha uma contrapartida social interessante, que era os estudantes virem fazer movimentos em Uibaí. Promoviam o futebol, o São João. E Enoch era um dos locutores das barracas de São João, uma espécie de agitador cultural. E ele sempre teve essa postura de liderança natural. Era nesses meandros aí da cultura de Uibaí que a gente [a geração de intelectuais da década de 1990] tinha conhecimento de Enoch ${ }^{11}$.

Nessa época muitos estudantes que participavam na organização, ou simplesmente eram espectadores da agitação política e cultural promovida pela AEUSU, tinham conhecimento de Enoch Carneiro através da sua poesia. Com a literatura de Enoch Carneiro, pela primeira vez na história de Uibaí um escritor conseguia ser uma referência intelectual para o público. Antes as referências eram apenas externas e distantes, principalmente as literárias. Na opinião de Pita Paiva, Carneiro desempenha uma performance de vanguarda, pois a sua iniciativa de escrever para a cidade:

Tem um valor enorme, pois quando ele se arvora em escrever e colocar o seu pensamento e divulgar o seu pensamento em livro, assanha um bocado de outros, leitores e possíveis escritores que vê

\footnotetext{
11 Pita Paiva, depoimento citado.
} 
isso mais de perto, com mais nitidez, com mais clareza. É alguém conhecido. De fato é a referên$\mathrm{cia}^{12}$.

É interessante apontar que Pita Paiva percebe Enoch Carneiro não como um escritor qualquer, mas como um escritor marginal, dentro de uma "escola literária”, com seus pressupostos, ideologia e estética próprias.

Houve todo um processo de percepção que fazia crescer, sobretudo no meio artístico da cidade, a figura de Enoch Carneiro com um modelo de escritor para além da palavra escrita. Perguntado sobre qual a influência de Enoch, enquanto intelectual, para a sua formação intelectual, Pita Paiva explica que:

\footnotetext{
Quando ele escreveu um livro Um nordestino em Moscou que contava a história do professor Hadi e toda aquela comunidade alternativa... A minha geração foi regada por esse sonho mais radical de uma utopia, um anarquismo. A gente de certa forma, deixava uma impressão que éramos anarquis$\operatorname{tas}^{13}$.
}

Paiva lembra que quando ele e seus colegas leram o livro “[...] estávamos naquela febre de ler escritores como Roberto Freire”. Afirma ser Enoch “[...] alguém que eu li todas as obras. Não tem como você sair ileso, de alguém do seu lugar em que você se inspira”. Segundo ele, poucos jovens de sua geração leram Enoch, isso ocorreu porque havia uma restrição ao círculo dos formadores de opinião e multiplicadores da cultura de esquerda, da qual Enoch Carneiro era filiado. Nesse ponto, vemos que a declaração de Pita Paiva reforça nossa hipótese de que Enoch é um escritor lido por intelectuais. Não seria escritor para um simples deleite, mas de formação, vanguarda e inspiração, em constante luta pela formação e continuação de uma contracultura local.

Quando perguntado se Enoch Carneiro representa uma contribuição para cultura e política de Uibaí, Pita Paiva declara que sim, ainda que indiretamente. Conta que sua geração conhecia os poemas de Carneiro com referências à participação social, como “Fichário” e “Merdobrás”. Pita Paiva diz que: “Tudo aquilo casava muito bem com a indignação social que a gente sentia e nos ajudava a refletir sobre uma realidade social. Então isso eu considero influência, uma contribuição”.

\footnotetext{
12 Pita Paiva, em depoimento antes citado.

13 Pita Paiva, em depoimento antes citado.
} 
Finalizamos a conversa com Pita Paiva perguntando o que significa para Uibaí e região ter um escritor como Enoch, considerando a Bahia oculta de escritores marginais. Paiva considera que Uibaí seja talvez a principal referência cultural do território de Irecê, ele acredita que:

Quando se tem alguns intelectuais que fazem acontecer um diferencial dentro da cultura da cidade o município se torna mais visto do ponto de vista positivo, e juntando a isso, se "pega" a obra de Enoch e a figura dele que vem com uma história de alguém que veio de uma família que não era abastada mas que ele conseguiu vencer na vida, ele alavancou os outros para poder fazer faculdade; passou pela CEU, que, enfim, enfrentou concurso, que, tem cargo público federal, que traz toda essa vida paralela a de escritor. Então, por toda essa história de vida ele já é um patrimônio imaterial desse lugar. Para nossa região e para o município em si ter alguém que produz que sempre produziu livro, eu acho que isso ajudou a fixar o nome desse município como terra da cultura.

\section{CONCLUSÃO}

A percepção da imagem intelectual de Enoch em sua região natal parece se dar de duas maneiras: a primeira diz respeito à sua contribuição, como intelectual, em um modelo militante - comum entre alguns escritores, como, por exemplo, Sartre, que se manifestava publicamente. A segunda ocorre em relação à sua contribuição por meio da palavra. Nesta, considerando-se os livros em si, vimos que para Pita Paiva a grande influência de Enoch foi como escritor. Em outras constatações, percebemos que a sua obra desempenha um papel de referencial teórico e instrumento simbólico que serviu de emblema, ao longo das duas últimas décadas, ao trabalho político que a geração posterior a Osvaldo Alencar desenvolveu na comunidade.

Além de referenciar uma geração nas mais diversas áreas artísticas, Enoch Carneiro constrói um tipo de literatura que tem como interlocutor principal a cidade. Nos final dos anos 80 e início de 90 ele funda duas entidades: a Fundação dos Artistas de Uibaí (FAU) e a Arte Som, associações que articuladas com a sua literatura foram dando à figura de Carneiro a representação de um agente cultural que lança mão de mais de um meio discursivo para por em debate as questões inerentes à sua comunidade, discursos estes norteados e permeados pela literatura. 


\section{REFERÊNCIAS}

DENIS, Benoit. Literatura e engajamento: de Pascal à Sartre. Trad. Luis Dagobert de Aguirra Roncari. Bauru: EDUSC, 2002.

SOUZA, Thana Mara de. Sartre e a literatura engajada. São Paulo: Edusp, 2008.

ROCHA, Osvaldo de Alencar; MACHADO, Edimário Oliveira. Canabrava do Gonçalo: uma vila do Baixo Médio São Francisco. Brasília: Ed. do Autor, 1988.

MARTINS, Flávio Dantas. Moradia e resistência estudantil. Feira de Santana, 2006.

DELEUZE, Gilles; GUATTARI, Félix. Kafka: para uma literatura menor. Trad. Rafael Godinho. Lisboa: Assirio e Alvim, 2003.

LEMOS, Maria Tereza Carneiro. A admissão do intelectual: literatura e poder no Brasil. Fólio, Revista de Letras, Vitória da Conquista, v. 2, n. 1, p. 70-86, jan. /jun. 2009.

RIBEIRO. Os herdeiros. In: MORGATO; GOMES (Org.). O papel do intelectual hoje. Belo Horizonte: Edtora UFMG, 2004, p. 70.

FOUCAULT, Michel. DELEUZE, Gilles. Os intelectuais e o poder. In: FOUCAULT, Michel. Microfísica do poder. Org. e trad. Roberto Machado. Rio de Janeiro: Graal, 1979, p. 41-46.

SPIVAK, Gayatri Chakravorty. Pode o subalterno falar? Trad. Sandra Regina Goulart Almeida et al. Belo Horizonte: Editora UFMG, 2010.

CARNEIRO, Enoch. Um nordestino em Moscou. Salvador: Bureau, 1990.

\section{Depoimentos:}

Depoimento de Pita Paiva, concedido a Eduardo Lopes, na localidade de Quixabeira, UibaíBA, em 2 de dezembro de 2012.

Depoimento de Enoch Carneiro, concedido a Eduardo Lopes, em Uibaí, em 5 de novembro de 2012.

Recebido em: 20 de setembro de 2013.

Aceito em: 30 de setembro de 2013. 
